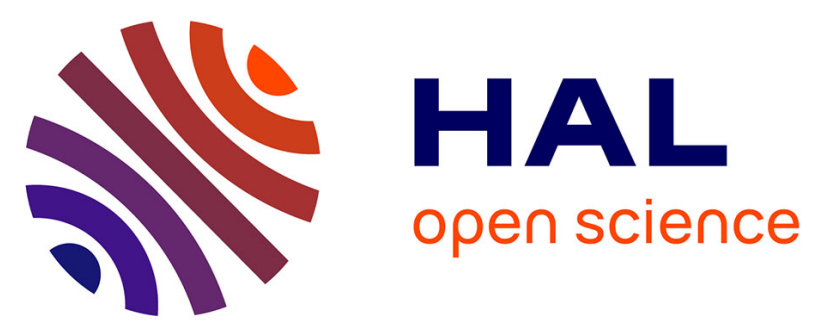

\title{
Recommended antimicrobial treatment of uncomplicated gonorrhoea in 2009 in 11 East-European countries - implementation of a Neisseria gonorrhoeae antimicrobial susceptibility programme in this region is crucial
}

\author{
Magnus Unemo, Elena Shipitsyna, Marius Domeika
}

\section{To cite this version:}

Magnus Unemo, Elena Shipitsyna, Marius Domeika. Recommended antimicrobial treatment of uncomplicated gonorrhoea in 2009 in 11 East-European countries - implementation of a Neisseria gonorrhoeae antimicrobial susceptibility programme in this region is crucial. Sexually Transmitted Infections, 2010, 86 (6), pp.442. 10.1136/sti.2010.042317 . hal-00557471

\section{HAL Id: hal-00557471 \\ https://hal.science/hal-00557471}

Submitted on 19 Jan 2011

HAL is a multi-disciplinary open access archive for the deposit and dissemination of scientific research documents, whether they are published or not. The documents may come from teaching and research institutions in France or abroad, or from public or private research centers.
L'archive ouverte pluridisciplinaire $\mathbf{H A L}$, est destinée au dépôt et à la diffusion de documents scientifiques de niveau recherche, publiés ou non, émanant des établissements d'enseignement et de recherche français ou étrangers, des laboratoires publics ou privés. 
Recommended antimicrobial treatment of uncomplicated gonorrhoea in 2009 in 11 East-European countries - implementation of a Neisseria gonorrhoeae antimicrobial susceptibility programme in this region is crucial

M Unemo, E Shipitsyna, M Domeika, on behalf of the Eastern European Sexual and Health (EE SRH) Network Antimicrobial Resistance Group ${ }^{\mathrm{a}}$

\section{Authors`affiliation:}

M Unemo, National Reference Laboratory for Pathogenic Neisseria, Department of Laboratory Medicine, Clinical Microbiology, Örebro University Hospital, Örebro, Sweden

E Shipitsyna, Laboratory of Microbiology, the D.O. Ott Research Institute of Obstetrics and Gynaecology, St. Petersburg, Russia

M Domeika, Department of Medical Sciences, Uppsala University, Uppsala, Sweden

Correspondence to: Magnus Unemo, National Reference Laboratory for Pathogenic Neisseria, Department of Laboratory Medicine, Clinical Microbiology, Örebro University Hospital, SE-701 85 Örebro, Sweden; magnus.unemo@orebroll.se

Running head: Treatment of gonorrhoea in Eastern Europe

Keywords: Neisseria gonorrhoeae, gonorrhoea, antimicrobial resistance (AMR), treatment, WHO, EE SRH Network, Eastern Europe

${ }^{\mathrm{a}} \mathrm{K}$ Babayan, M Aznauryan (Armenia); A Kengerli, V Eyvazov (Azerbaijan); N Sukhobokova, N Pankratova, I Shimanskaya, S Glazkova (Belarus); S Tchiokadze, G Galdava, O Kvivlidze (Georgia); T Brilene (Estonia); A Bayduysenova (Kazakhstan); G Mamayeva (Kyrgyzstan); S Polevschikova, N Frigo, A Savicheva (Russia); Z Yunusova (Tajikistan); N Kochetova, G Mavrov (Ukraine); S Ibragimov, A Davurov (Uzbekistan) 


\begin{abstract}
Antimicrobial resistance (AMR) in Neisseria gonorrhoeae (gonococcus) is a major problem worldwide. Quality-assured and quality-controlled AMR surveillance data on gonococci globally is crucial for public health purposes. In East-European countries, the knowledge regarding gonococcal AMR and its prevalence is limited.
\end{abstract}

Objectives: To ascertain the recommendations for antimicrobial treatment of uncomplicated gonorrhoea in 11 East-European countries; valuable information for introducing an international gonococcal AMR surveillance programme.

Methods: A questionnaire was used to collect information regarding the types, doses and manufacturers of the antimicrobials recommended for gonorrhoea treatment in all countries. Results: Ceftriaxone (250-1000 mg, intramuscularly (IM)×1) was reported as first-line antimicrobial in all countries $(\mathrm{n}=11)$. Many of the second-line and alternative treatments seemed suboptimal for empirical treatment. Regionally manufactured antimicrobials were predominantly used, were easily available and some may be of suboptimal quality. This generates effective prerequisites for emergence, and rapid spread of gonococcal AMR and gonorrhoea.

Conclusion: Ceftriaxone was first-line antimicrobial in all the 11 East-European countries, which is an appropriate choice also in a global perspective. However, the adherence, especially among private physicians, to these public sector recommendations is questionable. Implementation of national and international gonococcal AMR surveillance in this region is crucial; to provide evidence-based data for regular and timely updating of treatment guidelines, to identify emerging resistance, and to assist in the prevention, control and containment of gonococcal AMR and gonorrhoea. 
Gonorrhoea remains a major public health problem.[1] In East-European countries the incidence of gonorrhoea has generally been declining, but still remains high.[2]

Effective antimicrobial treatment is essential in gonorrhoea control.[3-6] However, the resistance in Neisseria gonorrhoeae (gonococcus) to all traditional gonorrhoea antimicrobials (penicillins, tetracycline, ciprofloxacin) is high and azithromycin resistance, including highlevel, has rapidly spread.[3] Extended-spectrum cephalosporins (ESCs) are currently the ideal treatment options. Nevertheless, the susceptibility to ESCs is decreasing worldwide, with treatment failures using oral ESCs such as cefixime occurring, especially in Japan.[3,7] Confirmed treatment failures of urogenital gonorrhoea using ceftriaxone (injectable), in an effective dose and of appropriate quality, are still lacking. However, two cases have been reported for pharyngeal gonorrhoea.[3] This is a serious concern globally and gonorrhoea may become untreatable in certain circumstances.

The WHO recently published initiatives to enhance global, quality-assured and qualitycontrolled, gonococcal antimicrobial resistance (AMR) surveillance.[3,8] Several gonococcal AMR programmes are operating at national and/or international level.[3] E.g., the European Union/European Centre for Disease Prevention and Control (EU/ECDC)-funded European gonococcal antimicrobial susceptibility programme (EURO-GASP) is operating in EU/EFTA countries.[5] However, valid AMR data are exceedingly scarce in many regions, including Eastern Europe. In this entire region, only Russia has a national gonococcal AMR programme (RU-GASP).[9]

The aims were to ascertain the recommendations for antimicrobial treatment of uncomplicated gonorrhoea in 11 East-European countries; valuable information for introducing an international gonococcal AMR surveillance programme, based on WHO protocols. $[3,8,10]$ 


\section{METHODS}

Eleven countries from the EE SRH Network [11] (Table 1) participated. STI Head specialists of their Health Ministries provided, through a questionnaire, in April-June 2009 information regarding the types, doses and manufacturers of the antimicrobials recommended for the gonorrhoea treatment.

\section{RESULTS}

First-line gonorrhoea treatment in all countries $(n=11)$ was ceftriaxone (injected intramuscularly [IM]); $250 \mathrm{mg}(\mathrm{n}=8), 1 \mathrm{~g}(\mathrm{n}=2)$, and $500 \mathrm{mg}(\mathrm{n}=1)$. Second-line was predominantly spectinomycin $(n=6)$, but cefixime $(n=1)$, azithromycin $(n=1)$, ciprofloxacin $(n=1)$, ofloxacin $(n=1)$, or roxithromycin $(n=1)$ was recommended in some countries. As alternative treatments, also antimicrobials such as kanamycin, erythromycin, and doxycycline were recommended. Some antimicrobials were used to cover both gonorrhoea and chlamydial infection.

High numbers of trademarks/manufacturers were reported for several antimicrobials, e.g. 24 different (from 13 countries) ones for ceftriaxone. It was impossible to trace some of the trademarks and/or to determine how widely used each of them was. However, in most countries predominantly antimicrobials manufactured nationally, regionally, or e.g. in India were used (Table 1).

\section{DISCUSSION}

This is the first study describing the antimicrobials recommended for gonorrhoea treatment in 11 East-European countries. In all countries, ceftriaxone (250-1000 mg, IM×1) was recommended as first-line, which is appropriate also in a global perspective.[3] However certainly not all, especially not private physicians, strictly adhere to these public sector 
recommendations. Accordingly, the present survey can not inform on the antimicrobials actually administered to all gonorrhoea patients in clinical practice. Further studies are in progress to determine what is actually being used in both public and private clinics. In general, it would be valuable to monitor and regulate the type of antimicrobials used, the amount of the different antimicrobials, the manufacturers of the antimicrobials, and the quality of the antimicrobials in all these countries. As second-line, spectinomycin was predominantly recommended. Spectinomycin is effective and resistance is rare worldwide.[3] However, resistance may rapidly emerge and has recently been reported in Russia.[3,9] Five countries reported using Trobicin, however, in 2005 Pfizer discontinued this production. In many countries, the recommendations of second-line and alternative treatments were suboptimal. Based on AMR data from Russia,[9] and worldwide,[3] many of these antimicrobials should not be used in empirical gonorrhoea treatment.

In most countries, antimicrobials manufactured nationally, regionally or in e.g. India were predominantly used, because of the higher costs of antimicrobials from internationally recognized companies. Some countries even mentioned treatment failures using regionally manufactured ceftriaxone, which presumably reflects suboptimal quality of the antimicrobial, however, this is crucial to confirm. In settings, such as most East-European countries, where antimicrobials are easily available and the quality of antimicrobials may be suboptimal, there is a substantially increased risk for emergence and rapid spread of gonococcal AMR and gonorrhoea.[3]

As the WHO has stated, to avoid making gonorrhoea untreatable under certain circumstances global initiatives integrating disease control and AMR containment are urgently needed.[3] The overuse and misuse of antimicrobials, including using antimicrobials of suboptimal quality, especially in settings where the disease control is insufficient, rapidly increase the AMR.[3] The WHO initiatives include enhanced global, quality-assured and 
quality-controlled, AMR surveillance, which is crucial for public health.[3,8] Valid AMR data are exceedingly scarce in many regions, including Eastern Europe beyond Russia.[9] Accordingly, implementation of local, national and international gonococcal AMR surveillance in the other East-European countries is crucial; to provide evidence-based data, regarding antimicrobials used for treatment, for regular and timely updating of STI management and treatment guidelines, to identify emerging resistance, and to assist in the prevention, control and containment of gonococcal AMR and gonorrhoea. $[3,4]$

In conclusion, this study ascertained the recommendations for antimicrobial treatment of gonorrhoea in 11 East-European countries. Ceftriaxone (250-1000 mg) was first-line antimicrobial in all the countries, which is an appropriate choice also in a global perspective. However, the adherence, especially among private physicians, to these public sector recommendations is questionable. This is valuable information for implementing an international gonococcal AMR surveillance programme in this region, based on WHO protocols, $[3,8,10]$ which is crucial for informing STI management and treatment guidelines for gonorrhoea and, accordingly, for public health.

Word count: 898 words

\section{Key messages}

- Antimicrobial resistance (AMR) in gonococci is an emergent problem. AMR surveillance globally is crucial for public health, however, is mainly lacking in Eastern Europe.

- Ceftriaxone (250-1000 mg) was reported as first-line treatment in all 11 surveyed East-European countries, which is an appropriate choice also in a global perspective. 
- Many of the second-line and alternative treatments seemed suboptimal. Antimicrobials were easily available and in most countries antimicrobials manufactured regionally were predominantly used.

- Implementation of gonococcal AMR surveillance in Eastern Europe is crucial; for appropriate updating of treatment guidelines, and assisting in gonorrhoea control and AMR containment.

\section{ACKNOWLEDGEMENT}

This study was supported by the EE SRH Network, and the WHO.

\section{CONTRIBUTOR}

MU in collaboration with MD initiated the study. MU and ES developed the questionnaire and translated it into Russian language. MD organised with the contacts in all the countries. MU and ES analysed the data and wrote the manuscript, in collaboration with MD.

\section{EXCLUSIVE LICENCE}

The Corresponding Author has the right to grant on behalf of all authors and does grant on behalf of all authors, an exclusive licence on a worldwide basis to the BMJ Publishing Group Ltd and its Licensees to permit this article (if accepted) to be published in STI and any other BMJPGL products and sub-licences such use and exploit all subsidiary rights, as set out in our licence http://group.bmj.com/products/journals/instructions-for-authors/licence-forms.

Conflict of interest: none.

\section{REFERENCES}


1. Schmid G. World Health Organization (WHO) 2005 global estimates of the incidence and prevalence of sexually transmitted infections (STIs). WHO/CDC symposium: congenital syphilis and the 2005 WHO estimates of STI incidence and prevalence: using the second to help eliminate the first. $18^{\text {th }}$ International Society for Sexually Transmitted Disease Research conference (ISSTDR), London, United Kingdom, 28 June to 1 July 2009.

2. WHO web site Gonorrhoea - Incidence rate (per 100,000 population). Published by World Health Organization Regional Office for Europe. Available at: Centralized information system for infectious diseases (CISID)/Sexually transmitted infections (STI) [http://data.euro.who.int/cisid].

3. Tapsall JW, Ndowa F, Lewis D, et al. Meeting the public health challenge of multi- and extensively-drug resistant Neisseria gonorrhoeae. Expert Rev Anti Infect Ther 2009;7:821-34.

4. Tapsall JW. Antimicrobial resistance in Neisseria gonorrhoeae WHO/CDS/CSR/DRS/2001.3. World Health Organization. Geneva 2001. Available from:

http://www.who.int/entity/drugresistance/Antimicrobial_resistance_in_Neisseria_gonorrh oeae.pdf

5. Martin IMC, Hoffman S, Ison CA. European surveillance of sexually transmitted infections (ESSTI): the first combined antimicrobial susceptibility data for Neisseria gonorrhoeae in Western Europe. J Antimicrobial Chemother 2006;58:587-93.

6. Roy K, Wang SA, Meltzer MI. Optimizing treatment of antimicrobial resistant Neisseria gonorrhoeae. Emerg Infect Dis 2005;11:1265-73.

7. Barry PM, Klausner JD. The use of cephalosporins for gonorrhea: the impending problem of resistance. Expert Opin Pharmacother 2009;10:555-77. 
8. Unemo M, Fasth O, Fredlund $\mathrm{H}$, et al. Phenotypic and genetic characterization of the 2008 WHO Neisseria gonorrhoeae reference strain panel intended for global quality assurance and quality control of gonococcal antimicrobial resistance surveillance for public health purposes. J Antimicrob Chemother 2009;63:1142-51.

9. Kubanova A, Frigo N, Kubanov A, et al. National surveillance of antimicrobial susceptibility in Neisseria gonorrhoeae in 2005-2006 and recommendation of first-line antimicrobials for gonorrhoea treatment in Russia. Sex Transm Infect 2008;84:285-9.

10. WHO Collaborating Centre for STD, Sydney. Rationale and applications for the current (2008) WHO panel of Neisseria gonorrhoeae for antimicrobial resistance surveillance for public health purposes, and instructions for their use. Technical document D007-0408-1\#1 2008.

11. Domeika M, Savicheva A, Sokolovskiy E, et al; Eastern European Network for Sexual and Reproductive Health (EE SRH Network). Quality enhancements and quality assurance of laboratory diagnosis of sexually transmitted infections in Eastern Europe. Int J STD AIDS 2009;20:365-7. 
Table 1 Recommendations for treatment of uncomplicated gonorrhoea in East-European countries*

\begin{tabular}{|c|c|c|c|}
\hline Country & First line $^{\dagger}$ & Second line $^{\dagger}$ & Alternative treatments ${ }^{\dagger}$ \\
\hline Armenia & Ceftriaxone $250 \mathrm{mg}, \mathrm{IM} \times 1$ & Ofloxacin $400 \mathrm{mg}, \mathrm{PO} \times 1$ & Cefixime $400 \mathrm{mg}, \mathrm{PO} \times 1$ \\
\hline Azerbaijan & Ceftriaxone $1 \mathrm{~g}, \mathrm{IM} \times 1$ & Spectinomycin $2 \mathrm{~g}, \mathrm{IM} \times 1$ & \\
\hline Belarus & Ceftriaxone $1 \mathrm{~g}, \mathrm{IM} \times 1$ & Spectinomycin $2 \mathrm{~g}$ (men), $4 \mathrm{~g}$ (women), IM $\times 1$ & $\begin{array}{l}\text { Azithromycin } 1 \mathrm{~g}, \mathrm{PO} \times 1 \\
\text { Doxycycline } 100 \mathrm{mg}, \mathrm{PO} \text { twice a day for } 7 \text { days }\end{array}$ \\
\hline Estonia & Ceftriaxone $250 \mathrm{mg}, \mathrm{IM} \times 1$ & Ciprofloxacin $500 \mathrm{mg}, \mathrm{PO} \times 1$ & Ofloxacin $400 \mathrm{mg}, \mathrm{PO} \times 1$ \\
\hline Georgia & Ceftriaxone $250 \mathrm{mg}, \mathrm{IM} \times 1$ & Azithromycin $1 \mathrm{~g}, \mathrm{PO} \times 1$ & Doxycycline $100 \mathrm{mg}$, PO twice a day for 7 days \\
\hline Kazakhstan & Ceftriaxone $250 \mathrm{mg}, \mathrm{IM} \times 1$ & Spectinomycin $2 \mathrm{~g}, \mathrm{IM} \times 1$ & \\
\hline Kyrgyzstan & Ceftriaxone $250 \mathrm{mg}, \mathrm{IM} \times 1$ & Spectinomycin $2 \mathrm{~g}, \mathrm{IM} \times 1$ & Ciprofloxacin 500, $\mathrm{PO} \times 1$ \\
\hline Russia & Ceftriaxone $250 \mathrm{mg}, \mathrm{IM} \times 1$ & Spectinomycin $2 \mathrm{~g}, \mathrm{IM} \times 1$ & \\
\hline Tajikistan & Ceftriaxone $250 \mathrm{mg}, \mathrm{IM} \times 1$ & Spectinomycin $2 \mathrm{~g}, \mathrm{IM} \times 1$ & Azithromycin $1 \mathrm{~g}, \mathrm{PO} \times 1$ \\
\hline Ukraine & Ceftriaxone $500 \mathrm{mg}, \mathrm{IM} \times 1$ & Cefixime $400 \mathrm{mg}, \mathrm{PO} \times 1$ & $\begin{array}{l}\text { Spectinomycin } 2 \mathrm{~g}, \mathrm{IM} \times 1 \\
\text { Kanamycin } 2 \mathrm{~g}, \mathrm{IM} \times 1\end{array}$ \\
\hline Uzbekistan & Ceftriaxone $250 \mathrm{mg}, \mathrm{IM} \times 1$ & Roxithromycin $150 \mathrm{mg}$, PO twice a day for 7 days & $\begin{array}{l}\text { Doxycycline } 100 \mathrm{mg} \text {, PO twice a day for } 5 \text { days; } \\
\text { Azithromycin } 1 \mathrm{~g}, \mathrm{PO} \times 1 \text {; } \\
\text { Kanamycin } 2 \mathrm{~g}, \mathrm{IM} \times 1 \text {; } \\
\text { Erythromycin } 500 \mathrm{mg} \text {, PO } 4 \text { times a day for } 7-14 \text { days (for }\end{array}$ \\
\hline
\end{tabular}


pregnant women)

IM, injected intramuscularly; PO, per os

*All countries belong to the WHO EURO region, are independent countries of the former Soviet Union, and are members of the EE SRH Network [11]. However, geographically they represent East-European countries (Belarus, Estonia, Russia, Ukraine), Caucasian countries (Armenia, Azerbaijan, Georgia), and Central Asian countries (Kazakhstan,

Kyrgyzstan, Tajikistan, Uzbekistan)

${ }^{\dagger}$ Manufacturer (country) of the antimicrobials used: ceftriaxone: Hoffman La Roche (Switzerland), World Medicine, Pliva Pharma, Mili Healthcare (UK), Medochemie (Cyprus), Pharmacare (Israel), Mustafa Nevzat Ilac Sanayii (Turkey), Lek (Slovenia), Polfa (Poland), Lekko, Synthesis, Kraspharma, Biosynthesis (Russia), Kievmedpreparat, Darnitsa,

Borshchahivskiy Chemical-Pharmaceutical Plant (Ukraine), Belmedpreparat, Belbiopharm (Belarus), Kefar (Kazakhstan), Dzhurabek (Uzbekistan), Square Pharmaceuticals (Bangladesh), Torrent Pharmaceuticals, Orchid Healthcare, Plethico Pharmaceuticals (India); spectinomycin: Pharmacia/Pfizer (Belgium/USA), Medochemie (Cyprus);

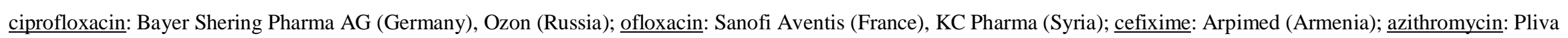
(Croatia), Pharmacare (Israel), Valenta (Russia), Pharmland (Belarus), Santo (Kazakhstan), Unique Pharmaceutical Laboratories (India); roxithromycin: Lek (Slovenia), Nobel Pharmsanoat (Turkey); doxycycline: Astellas Europe (Netherlands), Belbiopharm (Belarus), Lannacher Heilmittel (Austria), Stada Arzneimittel AG (Germany); kanamycin: Kievmedpreparat (Ukraine), Lvovtechnopharm (Ukraine), Unspecified (Russia and China); erythromycin: Teva Pharmaceutical Industries (Israel), Synthesis (Russia) 